\title{
Acute Suppurative Thyroiditis with Thyroid Abscess by Klebsiella pneumoniae: An Unusual Presentation
}

\author{
Prashant Nasa, K. G. Mathew', Rakesh Sanker ${ }^{2}$, Sandeep Chaudhary ${ }^{3}$, Vikas Singhal ${ }^{1}$ \\ Departments of Critical Care Medicine, ${ }^{1}$ Surgery, ${ }^{2}$ Internal Medicine and ${ }^{3}$ Endocrinology, NMC Speciality Hospital, Dubai, UAE
}

\section{Abstract}

Acute suppurative thyroiditis with thyroid abscess is very uncommon cause of thyroiditis. Thyroid infection in a diabetic patient is commonly labeled to the relative immunosuppressive state of diabetes mellitus. We present a case of a diabetic patient showing clinical symptoms of acute thyroiditis with progressing dysphagia, who was diagnosed as thyroid abscess as a result of Klebsiella pneumoniae. The infection in the absence of other significant history was initially considered de novo; however, on extensive evaluation was associated with other distant primary source of the same microbe. The patient was managed with minimally invasive drainage of abscess and intravenous antibiotics.

Keywords: Acute suppurative thyroiditis, Klebsiella pneumoniae, thyroid abscess

\section{INTRODUCTION}

The thyroid gland is inherited resistant to infection because of its rich vascular supply, well-developed capsule, and high iodine content. An infection in thyroid should be diagnosed with a high index of suspicion, and another primary source of infection should be searched especially in unusual microbes.

\section{Case Report}

A 40-year-old male presented to emergency room of our hospital with a history of fever, cough, severe neck pain, sore throat, and difficulty in deglutition of 1-week duration. He was a known case of diabetes mellitus following acute severe pancreatitis and pancreatic surgery 3 years back; now on mixed insulin 18 units 8 hourly and plain insulin 10 units afternoon. On examination, the patient was normal built, conscious, anxious, and febrile (temperature $39^{\circ} \mathrm{C}$ ). His vitals include heart rate 147 beats per minute, blood pressure $92 / 51 \mathrm{mmHg}, \mathrm{SpO}_{2} 95 \%$ on room air, and arterial blood gas showed mild metabolic acidosis with lactate of 2.7. A large tender midline swelling of approximately $5 \mathrm{~cm} \times 4 \mathrm{~cm}$, warm on touch, in the thyroid region, with erythema over the overlying skin [Figure 1]. The swelling moved with deglutition. The thyroid function tests showed hyperthyroidism with free T3 $8.86 \mathrm{pg} / \mathrm{ml}(1.71-3.71)$, free T4 more than $5 \mathrm{ng} / \mathrm{dl}(0.7-1.48)$, and very low thyroid-stimulating

\begin{tabular}{|l|l|}
\hline \multicolumn{3}{c|}{ Access this article online } \\
\hline Quick Response Code: & Website: \\
& www.ijccm.org \\
\hline
\end{tabular}

hormone $0.004 \mu \mathrm{IU} / \mathrm{ml}(0.35-4.94)$. His other significant laboratory investigations are seen in Table 1 . He was shifted to ICU and managed as per surviving sepsis guidelines with fluids, antibiotics (ceftriaxone and moxifloxacin) and other supportive management. The bedside ultrasound neck revealed diffuse hyperechoic swelling on the right side of the neck most likely originating from the right thyroid lobe with suspected air halos. After initial resuscitation patient was started on intravenous (IV) antibiotics (ceftriaxone and moxifloxacin), tablet propranolol $20 \mathrm{mg} 8$ hourly, hydrocortisone $50 \mathrm{mg}$ IV 8 hourly, and carbimazole $10 \mathrm{mg} 8$ hourly. Contrast-enhanced computed tomography (CT) scan of the neck revealed a large ill-defined area of peripherally enhancing collection with multiple compartments and multiple entrapped air pockets and areas of liquefaction suggestive of abscess arising from right lobe of thyroid with left lobe of thyroid appearing normal [Figure 2]. The diagnosis of thyroid abscess was made, and CT-guided drainage of $25 \mathrm{ml}$ of pus was done after $18 \mathrm{~h}$ of admission, and 8F catheter was left in situ [Figure 3]. The patient continued to have hoarseness of voice which on direct

Address for correspondence: Dr. Prashant Nasa, NMC Speciality Hospital, Dubai, UAE. E-mail: dr.prashantnasa@hotmail.com

This is an open access journal, and articles are distributed under the terms of the Creative Commons Attribution-NonCommercial-ShareAlike 4.0 License, which allows others to remix, tweak, and build upon the work non-commercially, as long as appropriate credit is given and the new creations are licensed under the identical terms.

For reprints contact: reprints@medknow.com

How to cite this article: Nasa P, Mathew KG, Sanker R, Chaudhary S, Singhal V. Acute suppurative thyroiditis with thyroid abscess by Klebsiella pneumoniae: An unusual presentation. Indian J Crit Care Med 2018;22:613-5. 


\begin{tabular}{|c|c|c|c|}
\hline Investigations (unit), (reference range) & Day 1 & Day 2 & Day 5 \\
\hline $\mathrm{Hb}(\mathrm{g} / \mathrm{dl})$ & 12.2 & 11.8 & 11.5 \\
\hline $\operatorname{TLC}\left(\times 10^{9} / \mathrm{L}\right),(\mathrm{DLC}(\%))$ & $20.89,(77,10,11,2)$ & $17.9,(67,23,7,3)$ & $12.4,(56,37,4,3)$ \\
\hline Platelets $\left(\times 10^{9} / \mathrm{L}\right)$ & 344 & 241 & 240 \\
\hline CRP (mg/L), procalcitonin (ng/ml) & $283,9.45$ & $247,8.68$ & $112,1.45$ \\
\hline Serum sodium, potassium, chloride (mmol/L) & $142,3.5,105$ & $138,4.1,107$ & $137,4.2,101$ \\
\hline Blood urea $(\mathrm{mg} / \mathrm{dl})$, serum creatinine $(\mu \mathrm{mol} / \mathrm{l})$ & $53,86.3$ & $45,67.8$ & $42,59.5$ \\
\hline $\mathrm{TSH}(\mu \mathrm{IU} / \mathrm{mL})$ & 0.004 & & \\
\hline Free T3 (pg/mL), Free T4 (ng/dL) & $8.86,>5$ & & $3.35,1.45$ \\
\hline HbA1c (\%) & 6.4 & & \\
\hline Antithyroglobulin $\mathrm{Ab}(\mathrm{U} / \mathrm{ml}),<34$ & 8.87 & & \\
\hline Antithyroid peroxidase $\mathrm{Ab}(\mathrm{U} / \mathrm{ml}),<115$ & 16.69 & & \\
\hline Anti-TSH receptor $\mathrm{Ab}(\mathrm{IU} / \mathrm{L}) \leq 1.75$ & 0.54 & & \\
\hline
\end{tabular}

Hb: Hemoglobin; HbA1c: Hemoglobin A1c; TLC: Total leukocyte count; DLC: Differential leukocyte count; CRP: C-reactive protein; TSH: Thyroid-stimulating hormone; Ab: Antibodies

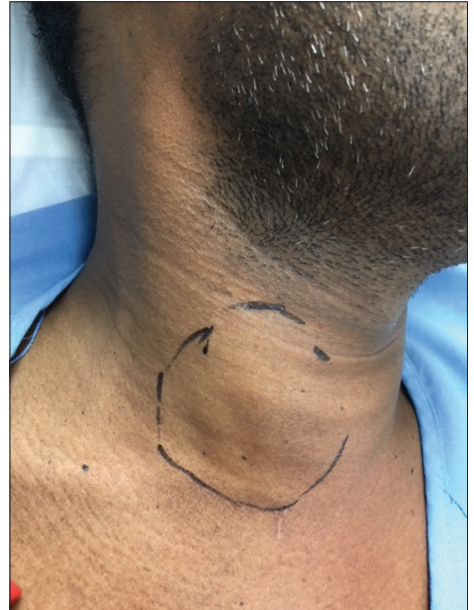

Figure 1: $5 \mathrm{~cm} \times 4 \mathrm{~cm}$ swelling in thyroid region with erythema over the overlying skin

laryngoscopy was found to be right vocal cord paralysis. The pus showed Klebsiella pneumoniae sensitive to ceftriaxone. The urine culture also showed $K$. pneumoniae with similar antimicrobial sensitivity profile. Ultrasound abdomen did not show any pyelonephritis but hypoechogenicity in urinary bladder suggestive of cystitis. His final diagnosis was acute suppurative thyroiditis, thyroid abscess, and thyrotoxicosis with diffuse goiter without thyroid crisis, urinary tract infection, right vocal cord palsy, and diabetes mellitus. The moxifloxacin was stopped and ceftriaxone was continued for 8 days. The patient condition improved and was discharged after on $9^{\text {th }}$ day. On 6-month follow-up, the patient continued to have mild hoarseness of voice with thyroid function recovered to normal.

\section{DISCUSSION}

Acute suppurative (microbial) thyroiditis (thyroid abscess) is an uncommon cause of thyroiditis because of inherent properties of the thyroid gland; rich blood supply, well-developed capsule, and high iodine content. ${ }^{[1]}$ In pediatrics, thyroid abscess is

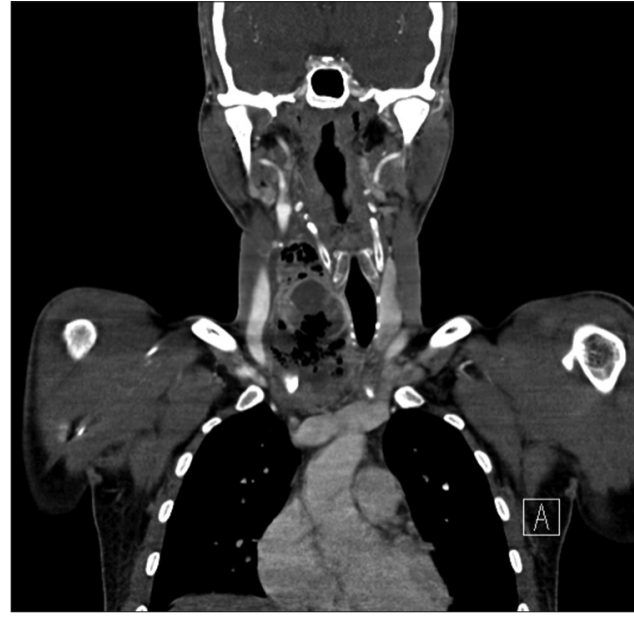

Figure 2: III-defined area of the collection with multiple compartments and multiple entrapped air pockets likely abscess arising from the right lobe of thyroid

seen with anatomical anomalies such as pyriform sinus fistula, brachial cleft fistula, or thyroglossal ducts. In adults besides above-mentioned anatomical anomalies, common association is either hematogenous or lymphatic spread from distant site, rarely direct contamination during fine-needle aspiration cytology procedure or trauma or immunosuppression due to any cause. ${ }^{[1,2]}$ The initial presentation is acute thyroiditis, and rarely an abscess may develop in advanced cases or virulent organism. ${ }^{[1-3]}$ Thyroid abscess is more common in females with the left side of gland is usually involved. ${ }^{[4,5]}$

Staphylococci and Streptococci are the common causes of acute suppurative thyroiditis. ${ }^{[4]}$ The other microbes described to be associated with thyroid abscess are Aspergillus, Brucella, Klebsiella, Eikenella, Escherichia coli, Salmonella, and Acinetobacter sp. and sometimes the infection is polymicrobial. ${ }^{[5]}$ The diagnosis is usually delayed because the presenting features are subtle. They mimic the symptoms of acute pharyngitis, with anterior neck pain, pyrexia, and odynophagia. ${ }^{[4]}$ Cutaneous erythema may also be present with 


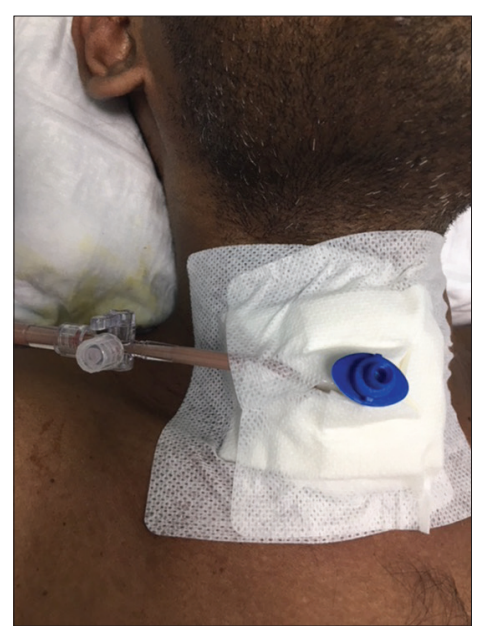

Figure 3: Computed tomography-guided drainage with $8 \mathrm{~F}$ catheter was left in situ

advanced infections as seen in this case. The thyroiditis may be associated with manifestations of hyperthyroidism and need standard management.

Our patient was male, with right lobe of thyroid involvement, did not have any other complaints of distant site infection, no previous history of thyroid disease, any direct trauma or procedure, and no anatomical anomaly was seen on CT scan. The only risk factor was diabetes but with good glycemic control. It is commonly presumed that diabetic patients are susceptible to infections. Thyroid abscesses are uncommon in modern medical practice. In the absence of no other symptoms, we initially considered de novo thyroid infection with preexisting diabetes in this patient. However, in suspicion of another source of primary infection, we send blood, and urine cultures and $K$. pneumoniae was positive in the urine culture with significant growth with same antimicrobial sensitivity profile as in pus from thyroid abscess.

The management of a thyroid abscess is source control, conventionally consisting of incision and drainage, combined with appropriate antibiotic therapy. ${ }^{[4]}$ Currently, there is a trend toward the minimally invasive techniques of surgical drainage of thyroid abscess instead open incision and drainage which have been found effective. ${ }^{[6]}$ The Gram-negative $K$. pneumoniae in thyroid abscess is very unusual and to our knowledge reported in English literature only five other times. ${ }^{[6-10]}$ In all these patients, the association with diabetes and other associated distant site of infection was common. In our patient, we found an association of urinary tract infection with thyroid abscess and CT-guided drainage of abscess with IV antibiotics eradicated the infection.

\section{Conclusion}

The thyroid abscess in adults is uncommon and very rarely infection is de novo, there should be high suspicion for another primary source of infection unless there is a history of the abnormal anatomy of gland and direct trauma. The minimally invasive drainage with appropriate antibiotics and other supportive care is effective management.

\section{Declaration of patient consent}

The authors certify that they have obtained all appropriate patient consent forms. In the form the patient(s) has/have given his/her/their consent for his/her/their images and other clinical information to be reported in the journal. The patients understand that their names and initials will not be published and due efforts will be made to conceal their identity, but anonymity cannot be guaranteed.

\section{Financial support and sponsorship Nil.}

\section{Conflicts of interest}

There are no conflicts of interest.

\section{References}

1. Cawich SO, Hassranah D, Naraynsingh V. Idiopathic thyroid abscess. Int J Surg Case Rep 2014;5:484-6.

2. Sen S, Ramakant P, Paul MJ, Jennifer A. Acute suppurative thyroiditis secondary to urinary tract infection by $E$. coli: A rare clinical scenario. BMJ Case Rep 2016;2016. pii: bcr2015213231.

3. Adeyemo A, Adeosun A, Adedapo K. Unusual cause of thyroid abscess. Afr Health Sci 2010;10:101-3.

4. McLaughlin SA, Smith SL, Meek SE. Acute suppurative thyroiditis caused by Pasteurella multocida and associated with thyrotoxicosis. Thyroid 2006;16:307-10.

5. Nishihara E, Miyauchi A, Matsuzuka F, Sasaki I, Ohye H, Kubota S, et al. Acute suppurative thyroiditis after fine-needle aspiration causing thyrotoxicosis. Thyroid 2005;15:1183-7.

6. Bukvic B, Diklic A, Zivaljevic V. Acute suppurative Klebsiella thyroiditis: A case report. Acta Chir Belg 2009;109:253-5.

7. Kim SJ, Chu ST, Lee KS, Nam SW, Choi JK, Chung JW, et al. Metastatic endophthalmitis and thyroid abscess complicating Klebsiella pneumoniae liver abscess. Clin Mol Hepatol 2018;24:88-91.

8. Liu Y, Yu S, Ren X, Qiao Y, Sun G. Klebsiella pneumoniae thyroid abscess complicated with esophagitis in a woman with newly diagnosed diabetes mellitus: A case report. J Diabetes Investig 2016;7:127-9.

9. Cannizzaro MA, Veroux M, La Ferrera MG, Marziani A, Cavallaro N, Corona D, et al. Klebsiella pneumoniae pulmonary infection with thyroid abscess: Report of a case. Surg Today 2008;38:1036-9.

10. Hien KS, Kheong LC. Acute suppurative thyroiditis presenting as A painless thyroid swelling. Malays Fam Physician 2006;1:54-7. 